Revista

Ibero-Americana

de Estratégıa

\title{
ALINHAMENTO ESTRATÉGICO DE SETORES OPERACIONAIS: O CASO DA COOPERATIVA AGROINDUSTRIAL DO NOROESTE DO PARANÁ
}

\author{
STRATEGIC ALIGNMENT OF OPERATIONAL SECTORS: THE CASE OF THE \\ COOPERATIVA AGROINDUSTRIAL DO NOROESTE DO PARANÁ
}

\section{EL ALINEAMIENTO ESTRATÉGICO DE SECTORES OPERACIONALES: EL CASO DE}

\section{LA COOPERATIVA AGROINDUSTRIAL DEL NOROESTE DE PARANÁ}

\section{Julio Ernesto Colla}

Mestre em Administração pela Universidade Federal do Paraná - UFPR

Professor e coordenador do curso de Administração da Universidade Estadual do Norte do Paraná UNESPAR

E-mail: juliocolla@gmail.com (Brasil)

\section{Andréia Borghesan}

Graduada em Administração pela Faculdade Intermunicipal do Noroeste do Paraná - FACINOR 


\title{
ALINHAMENTO ESTRATÉGICO DE SETORES OPERACIONAIS: O CASO DA COOPERATIVA AGROINDUSTRIAL DO NOROESTE DO PARANÁ
}

\section{RESUMO}

Pretende-se, por meio desse artigo, verificar a existência de alinhamento estratégico entre os setores operacionais e a diretoria executiva da empresa estudada em relação ao processo logístico da empresa Copagra de Nova Londrina-PR. O referencial teórico trata de estratégia e do alinhamento estratégico. A coleta de dados ocorreu por meio de entrevista semiestruturadas. O tratamento dos dados ocorreu pela aglutinação do material coletado em função das categorias de análise. Os resultados informam que o setor agrícola parece alinhado com os objetivos organizacionais, no que tange a aumentar sua capacidade de produção e a redução estratégica dos seus custos operacionais. Foi encontrado também alinhamento indireto com melhorar a qualidade do álcool produzido, aumento da eficiência da frota e melhoria de eficiência operacional. Não foi encontrado alinhamento com o objetivo atender mercados específicos de álcool. Com relação à destilaria, foi encontrado alinhamento somente com relação a atender mercados específicos de álcool. Foi encontrado alinhamento indireto com o objetivo de melhoria de eficiência operacional. Não foi encontrado alinhamento com os objetivos aumentar a capacidade de produção, redução estratégica dos custos e aumento da eficiência da frota. Dessa forma, parece que setor agrícola está mais bem alinhado com objetivos organizacionais quando comparado com a destilaria. As contribuições teóricas mais relevantes estão relacionadas ao fato de que os objetivos organizacionais podem não ter respaldo em toda organização, visto que os objetivos departamentais podem não ir ao encontro dos objetivos da organização.

Palavras-chave: Estratégia; Alinhamento Estratégico; Objetivos Organizacionais.

\section{STRATEGIC ALIGNMENT OF OPERATIONAL SECTORS: THE CASE OF THE COOPERATIVA AGROINDUSTRIAL DO NOROESTE DO PARANÁ}

\begin{abstract}
This article intends to verify the existence of strategic alignment between the operational sectors and the executive board of the company studied in relation to the logistic process of the company Copagra of the Nova Londrina-PR. The theoretical reference describes strategy and strategic alignment. The data collection was performed using semi-structured interviews. Data processing occurred by agglutination of material collected according to the categories of analysis. The results indicate that the agricultural sector seems aligned with the organizational objectives with respect to increase production capacity and strategic reduction of operational costs. Additionally, indirect alignment with improving the quality of alcohol produced, increasing the efficiency of the fleet and improving operational efficiency was discovered. Alignment has not been found to meet alcohol specific markets and the alignment distillery was found only in relation to meet specific markets of alcohol. Indirect alignment with the objective of improving operational efficiency was found. Not found were alignment with the objectives to increase production capacity, strategic cost reduction and increased efficiency of the fleet. The agricultural sector seems more closely aligned with organizational objectives when compared to a distillery. The most relevant theoretical contributions are related to the fact that organizational objectives cannot be backed by any organization since the departmental objectives may not meet the organization's objectives.
\end{abstract}

Keywords: Strategic; Strategic Alignment; Strategic Objectives.

Revista Ibero-Americana de Estratégia - RIAE, São Paulo, v. 10, n. 2, p. 118-139, mai./ago. 2011. 


\section{EL ALINEAMIENTO ESTRATÉGICO DE SECTORES OPERACIONALES: EL CASO DE LA COOPERATIVA AGROINDUSTRIAL DEL NOROESTE DE PARANÁ}

\section{RESUMEN}

Por medio de este artículo, se pretende verificar la existencia del alineamiento estratégico entre los sectores operacionales y la dirección ejecutiva de la empresa estudiada en relación al proceso logístico de la empresa Copagra de Nova Londrina-PR. El referencial teórico trata de estrategia y del alineamiento estratégico. Los datos fueron recolectados por medio de entrevistas semiestructuradas. El tratamiento de los datos fue hecho por la aglutinación del material recolectado en función de las categorías de análisis. Los resultados informan que el sector agrícola parece alineado con los objetivos organizacionales, en lo que se refiere a aumentar su capacidad de producción y reducción estratégica de sus costos operacionales. También se encontró un alineamiento indirecto con la mejoría de la calidad del alcohol producido, aumento de la eficiencia de la flota y mejoría de la eficiencia operacional. No se encontró alineamiento con el objetivo de atender mercados específicos de alcohol. Con respecto a la destilería, se encontró alineamiento solamente con relación a ayudar mercados específicos de alcohol. Fue encontrado alineamiento indirecto con el objetivo de mejoría de la eficiencia operacional. No se encontró alineamiento con los objetivos de aumentar la capacidad de la producción, la reducción estratégica de los costos y aumento de la eficiencia de la flota. De esa manera, parece que el sector agrícola está mejor alineado con los objetivos organizacionales cuando se comparó con la destilería. Las contribuciones teóricas más relevantes están relacionadas al hecho de que los objetivos organizacionales pueden no tener respaldo en toda la organización, una vez que los objetivos departamentales no pueden ir al encuentro de los objetivos de la organización.

Palabras-clave: Estrategia; Alineamiento Estratégico; Objetivos Organizacionales. 
Alinhamento Estratégico de Setores Operacionais: O Caso da Cooperativa Agroindustrial do Noroeste do Paraná

\section{INTRODUÇÃO}

Sob o aspecto acadêmico, os estudos relacionados ao alinhamento estratégico têm causado grande interesse, em razão de seu poder de auxiliar a encontrar respostas quanto aos questionamentos relacionados à melhor utilização dos recursos estratégicos de acordo com as particularidades do ambiente. Talvez porque o alinhamento auxilie no entendimento de desempenho superior de uma organização ante aos seus concorrentes que não obtém esse ajuste (Barney, 1996; Bulgacov et al, 2007; Costa, 2006; Hayashi et al, 2006; Quinn, 2006). É possível que o desalinhamento dos recursos estratégicos explique o desempenho negativo de algumas organizações. Os esforços no entendimento do alinhamento estratégico são percebidos pelo grande e crescente número de trabalhos publicados na área.

Nesse sentido, Powell (1992), diz que a capacidade de alinhamento das organizações é vista como um recurso estratégico, com condições de produzir resultados superiores, e, consequentemente, constitui importante fonte de vantagem competitiva para as organizações. Identifica-se o alinhamento estratégico sendo abordado em diferentes construtos: vertical e horizontal (Wunder, 2005), que são referidos tendo como base um contexto de corporações multinacionais, o que reflete a influencia dos ambientes interno e externo (Prieto, 2006; Prieto e Carvalho, 2004; Venkatraman e Camillus, 1984).

Sob o aspecto gerencial, a capacidade de ação em alinhar os recursos estratégicos, disponíveis pela organização por parte de seus gestores, parece ser determinante para altos desempenhos organizacionais, visto que o contrário tende a formar uma força centrífuga e destruir os esforços organizacionais. $\mathrm{O}$ alinhamento estratégico é um importante instrumento de gestão empresarial (Brodbeck e Hoppen, 2003) e é possível que esteja relacionado com o desempenho econômico, e este não é um evento isolado, mas um processo contínuo de adaptação e mudança (Henderson e Venkatraman, 1993; Venkatraman, 1990).

Os estudos que tratam sobre estratégia em geral e alinhamento estratégico, por decorrência, têm migrado de um pensamento fortemente racional e previsível para uma percepção de desenvolvimento da estratégia por meio de um processo incremental e social. Nessa esteira, reside a contribuição acadêmica desse artigo, pois com essa modificação na forma de percepção da estratégia, abre-se espaço para diversos estudos, incluindo-se esse artigo. Assim, tendo como base a construção social da estratégia, parte-se do pressuposto que os objetivos organizacionais não são fielmente refletidos nos setores da organização.

Diante do exposto, esse trabalho busca atingir o seguinte objetivo principal:_verificar $a$ existência de alinhamento estratégico entre os setores operacionais (agrícola e destilaria) e a 
diretoria executiva em relação ao processo logístico da empresa Copagra de Nova Londrina - PR. Para melhor operacionalização, tal objetivo foi especificado em: apresentar os objetivos da direção executiva da empresa e do departamento agrícola e destilaria; relatar os principais elementos estratégicos da empresa Copagra de Nova Londrina - PR; analisar o alinhamento estratégico entre o setor agrícola, destilaria e objetivos estratégicos da Copagra de Nova Londrina - PR, além de haver necessária e breve descrição da organização estudada.

Esse trabalho é composto de cinco elementos essenciais. No primeiro, é apresentado à justificativa e o objetivo geral, bem como os objetivos específicos. No segundo, trata da base teórica utilizada, onde são abordados assuntos sobre estratégia e alinhamento estratégico. No terceiro tópico elementar é demonstrado o procedimento metodológico utilizado. No quarto ponto elementar é realizada a apresentação e, em seguida, as análises do material coletado. Por fim, no quinto e último elemento é apresentada a conclusão e as recomendações para futuros trabalhos. Ao final do trabalho, é apresentada a bibliografia utilizada.

\section{REVISÃO BIBLIOGRÁFICA}

\subsection{ESTRATÉGIA}

Apesar de não haver uma definição aceita por todos, em “[...]função da natureza humana insistir em uma definição para cada conceito" (Mintzberg, 2006), o conceito de estratégia é o que mais atrai a atenção e, ao mesmo tempo, gera controvérsia, em ciências sociais, porque a estratégia é tanto arte quanto ciência (Magreta e Stone, 2003; Gimenez, 2000). Ainda que seja paradoxal, parece haver o consenso de que não há consenso (Bulgacov et al, 2007), visto que a estratégia é um conceito fugaz e abstrato (Ansoff e Mcdonnel, 1993).

O relacionamento da empresa com seu ambiente externo é a preocupação de Ansoff e McDonnel (1993) quando conceituam estratégia. Esse relacionamento acontece por meio de decisões sobre produtos e tecnologias a serem desenvolvidos, de onde e para quem os produtos serão vendidos, por meio da conquista de alguma vantagem sobre os concorrentes. Quinn (2006) define estratégia como um padrão ou plano que integra as principais metas e políticas e a sequência de ação da organização em um todo coeso. O autor também se refere à estratégia como um elemento alocador de recursos, baseado nas competências e deficiências da organização. Nesse mesmo sentido, Wernerfelt (1984) propõe que a estratégia está intimamente relacionada à incerteza, sendo essa incerteza minimizada pelo entendimento e compreensão dos recursos empresariais. 
Alinhamento Estratégico de Setores Operacionais: O Caso da Cooperativa Agroindustrial do Noroeste do Paraná

Barney $(1996,2006)$ inclui que os recursos e capacidades da empresa devem ser analisados sobre a questão de valor, raridade, imitabilidade e organização.

O conceito de estratégia também é colocado como composto de plano, pretexto, padrão, posição e perspectiva. A estratégia, como plano, é um curso de ação conscientemente pretendido; como pretexto, é uma manobra; como padrão, é uma consistência de um comportamento no decorrer do tempo; como posição, é um meio de localização no ambiente e, como perspectiva, a maneira central de se realizar algo (Mintzberg, 2006; Mintzberg, Ahlstrand e Lampel, 2000). Para Porter (1996, 2004, 2006, 2008), estratégia é o gerenciamento das atividades para a busca de uma posição na indústria que gere vantagem competitiva sustentável em longo prazo, sendo moldada por cinco forças (a ameaça de novos entrantes, o poder de negociação dos fornecedores e dos compradores, a ameaça de produtos ou serviços substitutos e a rivalidade entre as empresas existentes em uma indústria que influencia a indústria). Dessa forma, eficácia operacional não é estratégia, pois é apenas um elemento de gestão (Porter, 1996, 2004, 2006, 2008).

Em uma perspectiva contemporânea, Whittington (2002) apresenta a visão da estratégia como um elemento social. Assim a estratégia pode ser percebida como um elemento construído por meio das interações sociais dos participantes de uma organização. O mesmo autor (2002) apresenta uma taxonomia a respeito de perspectivas da estratégia, em que surgem os clássicos, propondo estratégia como um processo racional de criação, cujo objetivo é maximizar a vantagem em longo prazo. Haveria, portanto, os evolucionistas, para quem o planejamento racional é descartado, pois as forças do ambiente são implacáveis; os processualistas, que sugerem que os mercados e as organizações são imperfeitos e, portanto, os planejamentos clássicos podem não ser úteis, uma vez que também não concordam com a ideia da sobrevivência organizacional; e os sistêmicos, que identificam a estratégia como sendo de grande importância para a organização, mas não no mesmo nível dos clássicos.

\subsection{ALINHAMENTO ESTRATÉGICO}

O conceito de alinhamento estratégico difere entre autores, entretanto, é ponto comum que esse não é um assunto simples, pois muitas variáveis e fatores o influenciam. De maneira geral, o termo é utilizado em relação a ajustes entre elementos organizacionais ou ambientais, geralmente sujeitos à alterações típicas das pressões exercidas por sistemas abertos em permanente disputa por inputs e outputs diversos, tais como energia, matéria e informações (Barros, 2007; Fernandes Filho, 2003).

Revista Ibero-Americana de Estratégia - RIAE, São Paulo, v. 10, n. 2, p. 118-139, mai./ago. 2011. 
Por outra linha de pensamento teórico, alinhamento estratégico corresponde à adequação e integração funcional entre ambientes externo e interno para desenvolver as competências e maximizar o desempenho organizacional (Synnott, 1987; Henderson e Venkatraman, 1990.

$\mathrm{O}$ alinhamento estratégico tanto como um processo quanto como um resultado é uma dinâmica que procura ajustar a organização com o seu ambiente e, internamente, organizar os recursos que dão suporte a tal alinhamento (Miles e Snow, 1984) e possui o sentido de agrupamento, coesão, ajuste, congruência, entre diferentes dimensões (Galbraith e Kazanjian, 1986).

Do ponto de vista estratégico e sistêmico, alinhamento estratégico refere-se à complexidade e interdependência dos seus sistemas abertos, cujos elementos formais (tecnologia, estratégia e estrutura) e informais (pessoas, líderes e valores) necessitam estar alinhados (ajustados), para que se dê a implementação eficaz das suas estratégias (Beer e Eisenstat, 1996).

A literatura, via de regra, trata do alinhamento entre a estratégia e a ação. Nesse sentido, Fahey (1994) comenta que para transformar a estratégia em ação, o gestor necessita ajustá-la aos processos, fazendo com que os considerados críticos também fiquem alinhados e não sejam apenas colocados no lugar certo. $\mathrm{Na}$ verdade, são diversas as combinações de sistemas no contexto de alinhamento estratégico.

Na lógica estratégica de não separação do pensamento da ação (Mintzberg, Ahlstrand, e Lampel, 2000), pode-se encontrar o alinhamento da alta administração com a gerência intermediária (Eisenstat e Beer, 1994), e das pessoas que elaboram os planos e aqueles que os colocam em prática (Fischmann, 1987). Também há o alinhamento da estratégia com a estrutura da organização (Eisenstat e Beer, 1994; Wright, Kroll e Parnell, 2000).

Pode-se verificar também o alinhamento com o principal produto e com as variáveis de segmentação do mercado (Freedman, 2003) como um dos critérios utilizados no desenho da estrutura para garantir alinhamento. De toda forma, é necessário o alinhamento de longo e de curto prazo (Allio, 2005), com o objetivo de lidar com incertezas futuras. Para isso, se propõem o alinhamento pelo estabelecimento de metas de curto prazo decorrentes dos planos de prazo mais longo.

A partir do momento em que há o alinhamento completo entre os elementos da organização, ocorre a efetividade da estratégia. Colla (2009) coloca que a efetividade da estratégia se dá quando há alinhamento total entre os setores operacionais da organização com a missão organizacional. Dessa forma, o alinhamento estratégico parece ser a aptidão dos setores organizacionais em realizarem ações acopladas aos interesses estratégicos organizacionais

Sob a perspectiva gerencial, a lógica do Balanced Scorecard (Kaplan e Norton, 1997), é uma proposta conceitual que aponta na direção, de promover o desdobramento da missão e visão da 
Alinhamento Estratégico de Setores Operacionais: O Caso da Cooperativa Agroindustrial do Noroeste do Paraná

organização até níveis operacionais, segundo a lógica dos indicadores de desempenho balanceados e agrupados em vista: a financeira, de clientes, de processos, e a de inovação e crescimento. A relação causa e efeito dos indicadores estratégicos dá a tônica da relação da proposta de alinhamento estratégico (Oliveira, Cameira e Caulliraux, 2003).

\section{PROCEDIMENTOS METODOLÓGICOS}

Essa pesquisa tem caráter qualitativo. Tal escolha ocorreu porque esse tipo de pesquisa pode valer-se de muitas técnicas para investigação com diferentes tipos de suposições, com a intenção de aprofundar os conhecimentos sobre determinado assunto, enfatizando a importância de compreender os processos nos quais os seres humanos criam a realidade (Morgan e Smirich, 1980). Sua natureza é descritiva, uma vez que com essa tipologia é possível conhecer as características, estabelecer relações entre as categorias analisadas, bem como é possível ao pesquisador a utilização de documentos como fonte de análise (Creswell, 2007; Hair, Babin, Money e Samouel, 2005). Sua natureza é também explicativa, porque identifica os fatores que determinam ou contribuem para a ocorrência dos fenômenos, sendo aquela que mais se aprofunda no conhecimento da realidade, porque explica o porquê das coisas (Gil, 1991; Richardson, 1989).

Os dados foram coletados por meio de gravação, com posterior transcrição de entrevistas semiestruturadas realizadas com dois dirigentes estratégicos da organização, Vice-Presidente e Superintendente Industrial, e dois dirigentes de nível tático, Coordenador do Setor Agrícola e Encarregado de Transportes. A escolha dos respondentes se deu em razão da possibilidade do respondente ocupar um cargo que pudesse auxiliar o atingimento do objetivo desse trabalho, bem como o fato de que o alinhamento estudado nesse artigo está relacionada à atividade com cana-deaçúcar. Outro ponto importante para o obtenção de dados foi a pesquisa documental e a observação não-participante. A observação não-participante foi realizada por meio de frequentes visitas à empresa durante o período de coleta de dados e à confecção de diários de visitas.

A unidade de análise foi constituída por cada um dos dirigentes da empresa e o nível de análise foi constituído pelo organizacional, na perspectiva departamental e total (Flick, 2004; Creswell, 2007; May, 2004). A perspectiva temporal da pesquisa é transversal, e a coleta de dados ocorreu nos meses de setembro, outubro e novembro de 2009. Foi utilizada também a análise documental (Creswell, 2007, Flick, 2004; Triviños, 1987; May, 2004) para a descrição da organização estudada. O tratamento dos dados ocorreu pela reunião do material coletado em razão das categorias de análise que nortearam a análise interpretativa.

Revista Ibero-Americana de Estratégia - RIAE, São Paulo, v. 10, n. 2, p. 118-139, mai./ago. 2011. 
As principais limitações da pesquisa ocorreram em razão de que os vieses pessoais podem interferir nos resultados, principalmente se se tratar de estudo em que os pesquisadores são inseridos no interior das organizações, a fim de obter os dados primários (aplicação de questionários e observação não-participante) para a análise. Pode ter havido prejuízos na coleta de dados pelas limitações cognitivas dos respondentes. Soma-se a isso a limitação cognitiva dos próprios pesquisadores, pois há uma grande dificuldade de se manter uma postura de imparcialidade ou mesmo de não envolvimento, ainda que de forma inconsciente, mesmo buscando-se a eliminação da emissão de juízo de valor. Esse artigo também apresenta como limitação o fato de haver estudado apenas aspectos internos da organização e não a relação da organização como um todo e seu ambiente.

\section{APRESENTAÇÃO E ANÁLISE DOS RESULTADOS}

\subsection{APRESENTAÇÃO DA ORGANIZAÇÃO ESTUDADA}

A organização em estudo, Cooperativa Agroindustrial do Noroeste do Paraná (Copagra), possui 48 anos de fundação, 2447 associados e atua, de maneira intensiva, em três estados brasileiros (Paraná, São Paulo e Mato Grosso do Sul). Idealizada com a intenção de possibilitar melhor comercialização de café aos seus associados, atualmente exerce atividades nas culturas de cana-de-açúcar para produção de álcool anidro, álcool hidratado, álcool industrial e, futuramente, o açúcar; arroz; milho; soja; mandioca, para a produção de fécula e amidos modificados; café e leite, além do fornecimento de insumos agropecuários e assistência técnica para seus cooperados. Possui também incursões no comércio varejista de combustíveis.

Atualmente possui 1.600 empregados, com a maioria empregada na atividade canavieira. Sua estrutura organizacional conta com duas superintendências subordinadas à Diretoria Executiva. Essas superintendências correspondem à Administrativa e Financeira (com oito gerências) por um lado, e a Superintendência Industrial (com duas gerências), por outro.

A organização também opera em coligação com outras cooperativas ou empresas com o intuito de favorecer seus associados, entre elas a Cooperativa Central Agro Industrial de Londrina (Confepar), constituída por oito cooperativas. Também é coligada da Central Paranaense de Álcool (CPA Trading S/A), composta por 12 empresas. Essa central mantém dois terminais de açúcar e álcool, sendo um deles em Sarandi-PR. e outro em Paranaguá-PR. Outro empreendimento que é associada é a Álcool do Paraná S/A (APPA), composta por 18 empresas, e que recentemente inaugurou um terminal de álcool em Paranaguá-PR. 


\subsection{ELEMENTOS ESTRATÉGICOS DA ORGANIZAÇÃO ESTUDADA}

Os dados da pesquisa (entrevistas e diversos documentos analisados) possibilitaram a percepção dos pontos estratégicos da Copagra com relação ao negócio cana-de-açúcar, que são relatados no quadro 1:

\begin{tabular}{|c|c|}
\hline OBJETIVO & DESCRIÇÃO \\
\hline $\begin{array}{c}\text { Melhorar a } \\
\text { qualidade do } \\
\text { álcool produzido. }\end{array}$ & $\begin{array}{l}\text { A organização estudada percebe que existe potencial de expansão quantitativa no } \\
\text { momento e, dessa forma, canaliza suas atenções na melhoria da qualidade do álcool } \\
\text { produzido. Com essa ação, busca atender aos mercados japonês, chinês e norte- } \\
\text { americano. } \\
\text { Um fato que ajuda as cooperativas do Paraná, em geral, e a cooperativa estudada, em } \\
\text { específico, na competição por qualidade é que estas são conhecidas por não produzirem } \\
\text { álcool residual, ou seja, o álcool produzido depois da produção do açúcar. } \\
\text { A busca pelo aumento da qualidade do álcool produzido também se dá pelo fato de que } \\
\text { os clientes pedem etanol de diversas especificidades, o que constitui um padrão para } \\
\text { cada cliente. }\end{array}$ \\
\hline $\begin{array}{l}\text { Atender } \\
\text { mercados } \\
\text { específicos de } \\
\text { álcool }\end{array}$ & $\begin{array}{l}\text { As cooperativas se tornaram conceituadas em relação à qualidade do álcool pelo motivo } \\
\text { da não produção do álcool residual e em, razão disso, é possível trabalhar com alguns } \\
\text { alcoóis específicos e atender mercados específicos com álcool diferenciado. } \\
\text { Praticamente esse é o foco da cooperativa estudada. Dessa forma, é possível a busca de } \\
\text { diferenciais em relação ao preço. }\end{array}$ \\
\hline $\begin{array}{l}\text { Aumentar a } \\
\text { capacidade de } \\
\text { produção }\end{array}$ & $\begin{array}{l}\text { Após o período de estagnação do mercado internacional do etanol, a organização } \\
\text { estudada pretende aumentar a capacidade instalada em } 600.000 \text { toneladas, o que } \\
\text { representa incremento de } 60 \% \text { da capacidade atual. }\end{array}$ \\
\hline $\begin{array}{l}\text { Redução } \\
\text { estratégica dos } \\
\text { custos }\end{array}$ & $\begin{array}{l}\text { Em outra vertente estratégica, a organização busca redução de custos por meio da } \\
\text { diminuição do valor pago em frete para a matéria-prima. A preocupação em ter a cana } \\
\text { mais próxima dá-se pelo fato de que o frete é custo direto. O frete da matéria-prima é um } \\
\text { elemento que pode viabilizar ou não uma lavoura de cana-de-açúcar. }\end{array}$ \\
\hline $\begin{array}{c}\text { Aumento da } \\
\text { eficiência da frota }\end{array}$ & $\begin{array}{l}\text { Na mesma vertente da redução estratégica de custos, está o fato de o aumento do fluxo } \\
\text { de carga por vias específicas, ou seja, elevar a tonelagem transportada das atuais } 35 \text { para } \\
60 \text {. A atual média de tonelagem transportada se dá em razão da legislação de trânsito não } \\
\text { permitir, por isso, a cooperativa pretende melhorar algumas estradas vicinais, com vistas } \\
\text { a construir uma transcanavieira. Essa transcanavieira faria com que a operação das } \\
\text { carrocerias rebocadas aumentasse de três por rebocador para seis. } \\
\text { A busca da construção de uma estrada transcanavieira fez com que a cooperativa } \\
\text { buscasse modificar a posição geográfica das fazendas produtoras de cana-de-açúcar. } \\
\text { Outra linha de ação tomada pela cooperativa se dá no sentido de articular com o poder } \\
\text { público, a construção de um anel rodoviário na cidade de Nova Londrina, cidade onde é } \\
\text { a sede da cooperativa e opera a planta da destilaria. }\end{array}$ \\
\hline
\end{tabular}

Revista Ibero-Americana de Estratégia - RIAE, São Paulo, v. 10, n. 2, p. 118-139, mai./ago. 2011. 
Melhoria da

eficiência

operacional

Melhorar as deficiências com relação ao custo de corte, carregamento e transporte

(CCT). Para tanto, se deve melhorar a relação entre o custo de fabricação e o CCT.

Quadro 1- Objetivos organizacionais da Copagra.

As diretrizes administrativas da atividade cana-de-açúcar (nesse trabalho, utilizado como referência para o estudo do alinhamento) visam à busca pela sua estabilidade econômica, por meio de novos nichos de mercados para o álcool não só para fins de combustível, mas também com finalidade de utilização industrial ou para um fim especifico tanto no mercado interno quanto no mercado externo.

\section{OBJETIVOS DEPARTAMENTAIS}

\subsection{DEPARTAMENTO AGRÍCOLA}

Sob a perspectiva operacional, o setor de transporte é responsável pela entrega da cana-deaçúcar na destilaria em condições aptas para a moagem. A condição ideal de moagem é obtida diante de duas situações distintas: a primeira, quando a cana-de-açúcar não ultrapassa o ciclo normal de maturação, ou seja, a colheita é realizada em período futuro da maturação ideal; a segunda condição se dá quando a cana-de-açúcar não cresce além do esperado, o que ocasiona prejuízo na moagem da matéria-prima na destilaria por meio de entupimento das moendas, bem como faz diminuir a densidade da carga, pois há dobradura da cana-de-açúcar transportada. Dessa forma e diante do acima exposto, é encontrado que o objetivo primeiro do setor de agrícola é sustentar as operações da destilaria de álcool com a quantidade adequada de cana-de-açúcar para que não haja desabastecimento do sistema produtivo.

Ao setor agrícola, é indispensável a manutenção de estreito relacionamento com outros departamentos. Um fator que ilustra essa forte necessidade ocorre no plano de expansão operacional da destilaria. Nesse sentido, o departamento agrícola ganha destaque porque quando há expansão de planta fabril o primeiro passo é "plantar a cana [...]. Quando se faz um projeto, primeiro começa a cana. A cana e alguns equipamentos" (entrevistado 4). Surge assim o segundo objetivo do setor agrícola: sustentar o crescimento das operações.

Por outro lado, também há a necessidade de planejamento operacional antes do inicio de uma safra. Assim reúnem-se os envolvidos, abrangendo desde a compra e arrendamento e de áreas 
Alinhamento Estratégico de Setores Operacionais: O Caso da Cooperativa Agroindustrial do Noroeste do Paraná

próprias e de cooperados, passando pela preparação de solo, plantio, corte e carregamento até o transporte. Daí surge que outro objetivo do setor agrícola é dar sustentação às operações da destilaria.

Partindo desse pressuposto, a cooperativa foca em um planejamento em que a distância entre as plantações de cana-de-açúcar e a indústria fique cada vez mais curta e assim, cada vez mais, supra as necessidades da empresa que é de reduzir custo. Nesse sentido, a distância é o fator de maior importância nos custos do transporte, pois contribui diretamente para as despesas variáveis, mão-de-obra, combustível e manutenção. Assim, contribuir para a redução dos custos operacionais é objetivo do setor agrícola da cooperativa estudada.

Na esteira do objetivo de manutenção do abastecimento de matéria-prima, há no setor de transportes, na utilização de equipamentos e frotas, uma mescla de transportes próprios e terceirizados. Nesse sentido, o setor agrícola fez a opção de não realizar terceirização no maquinário essencial à colheita, para que não houvesse a dependência externa em fator tão importante de produção. Há a terceirização apenas no transporte. Assim, o quinto objetivo do setor agrícola é manter internamente atividades essenciais para as operações.

Em outro campo, porém essencial, é válido lembrar que a colheita da cana-de-açúcar era totalmente manual há alguns anos e que esse tipo de colheita, tem sido substituído, parcial ou totalmente, por máquinas. "No caso da cooperativa essa mudança vem ocorrendo lentamente, pois seu sistema é de corte manual e máquinas só para o carregamento da cana-de-açúcar” (entrevistado $1)$.

No entanto, estudos mostram que na colheita feita com a foice (manual), as perdas raramente ultrapassam 5\%. Já com as máquinas, esse percentual pula para 15\%, fato que se reflete diretamente na produtividade (Mello, 2005). Soma-se a isso, o fato de que na colheita mecanizada, ela é dificultada pelas áreas de topografia acidentadas com declive que existem na região onde está localizada a empresa estudada. Desse modo, o sexto e sétimo objetivos levantados no setor agrícola, a autopreparação para a mecanização da colheita e a contribuição para a redução dos custos operacionais da cooperativa estudada parece não estarem alinhados entre si.

No processo de corte, carregamento e transporte da cana-de-açúcar, há muita influência de fatores climáticos, o que faz com que haja substancial aumento dos custos de produção envolvidos na atividade. Dessa forma, a minimização da influência climática no processo de CCT é o oitavo objetivo do setor de transportes na organização estudada.

O quadro 2 sintetiza os objetivos do setor agrícola da Copagra.

Revista Ibero-Americana de Estratégia - RIAE, São Paulo, v. 10, n. 2, p. 118-139, mai./ago. 2011. 


\begin{tabular}{|c|l|}
\hline OBJETIVO & \multicolumn{1}{c|}{ DESCRIÇÃO } \\
\hline Objetivo 1 & Alimentar a destilaria de álcool com a quantidade adequada de matéria-prima. \\
\hline Objetivo 2 & Sustentar o crescimento das operações. \\
\hline Objetivo 3 & Dar sustentação às operações da destilaria. \\
\hline Objetivo 4 & Contribuir para a redução dos custos operacionais. \\
\hline Objetivo 5 & Manter internamente atividades essenciais para as operações. \\
\hline Objetivo 6 & Autopreparação para a mecanização da colheita \\
\hline Objetivo 7 & Contribuir para a redução dos custos operacionais da cooperativa estudada. \\
\hline Objetivo 8 & A minimização da influência climática no processo de CCT \\
\hline
\end{tabular}

Quadro 2- Objetivos do setor agrícola da Copagra.

\subsection{DESTILARIA}

A agroindústria de cana-de-açúcar produz uma variedade de produtos intermediários por meio de sua matéria-prima, o que possibilita diversas oportunidades de negócios. Além do etanol e do açúcar, uma destilaria de álcool também se dedica a produção de energia elétrica, material carburante para caldeiras, ração animal até a fabricação de material sólido para a construção civil e artesanato.

Atualmente, a destilaria estudada produz álcool hidratado e anidro, material carburante para caldeiras e energia elétrica, que é utilizada para o abastecimento da própria da destilaria e da fecularia, planta industrial que trata do processamento de raiz de mandioca, também de posse da Copagra. A cooperativa estudada pretende, em um futuro próximo, começar a produzir energia de fornecimento para a empresa distribuidora varejista oficial, por meio de biomassa. Operacionalmente significa que deixará de produzir material carburante para caldeira, que, apesar de renovável, é altamente poluidor, por algo mais sensível ecologicamente e lucrativo. Diante disso, surgem alguns objetivos da destilaria de álcool, que são: aumentar a produção de energia elétrica, por meio de biomassa, e entrar no negócio de energia elétrica. 
Alinhamento Estratégico de Setores Operacionais: O Caso da Cooperativa Agroindustrial do Noroeste do Paraná

O etanol é um produto amplamente utilizado como combustível automotivo, isoladamente ou misturado à gasolina, ou seja, o mercado carburante opera com dois tipos de etanol: o anidro e o hidratado. O etanol hidratado carburante é o utilizado nos carros e o etanol anidro carburante é utilizado na mistura da gasolina. Há também o uso não-carburante do etanol. Nesses casos, ocorre a utilização hospitalar e industrial. Esse último mercado, basicamente internacional, é o visado pela cooperativa estudada. Atualmente cerca de $20 \%$ da sua produção vai para esse mercado industrial e o restante vai para o mercado carburante. Dessa forma, o terceiro e quarto objetivos da destilaria são, respectivamente, auxiliar no aumento da participação do mercado de etanol industrial nos negócios da cooperativa e na diversificação do negócio cana-de-açúcar.

Os preços no mercado de etanol hidratado carburante são bastante pressionados, pois existe a presença de apenas cinco compradores desse tipo de etanol no Brasil, e estes exercem políticas de preço bastante prejudiciais aos fornecedores. Assim, o quinto objetivo da destilaria é diminuir a dependência dos grandes compradores nacionais de etanol hidratado carburante.

Em razão das características comerciais do etanol, principalmente pelo fato de não estar inserido na matriz energética oficial, seu mercado não ser commodityzado, não possuir um modelo negocial mundial, bem como não tem um padrão de qualidade padronizado, a comercialização ocorre de acordo com o pedido dos clientes, diferentemente do açúcar, que possui um espaço negocial, ou seja, tem um preço negociado mundialmente. Esse fato parece transitar entre a maior preocupação e o maior desejo mercadológico da organização estudada. Se, por um lado, há a não existência de um mercado commodityzado, porém previsível, o que exige maior efetividade gerencial, por outro, é uma maneira de obter maior ganho de mercado e lucratividade. Antagonicamente aos demais objetivos, o sexto objetivo da destilaria é participar mais efetivamente dos negócios commodityzados, pois garantem previsibilidade de operação.

O quadro 3, a seguir, sintetiza os objetivos da destilaria da Copagra.

\begin{tabular}{|c|l|}
\hline OBJETIVO & DESCRIÇÃO \\
\hline Objetivo 1 & Aumentar a produção de energia elétrica por meio de biomassa \\
\hline Objetivo 2 & Entrar no negócio de energia elétrica. \\
\hline Objetivo 3 & Auxiliar no aumento da participação do etanol industrial nos negócios da cooperativa \\
\hline
\end{tabular}

Revista Ibero-Americana de Estratégia - RIAE, São Paulo, v. 10, n. 2, p. 118-139, mai./ago. 2011. 


\begin{tabular}{|l|l|}
\hline Objetivo 4 & Auxiliar a diversificação do negócio cana-de-açúcar. \\
\hline Objetivo 5 & Diminuir a dependência dos grandes compradores de etanol hidratado carburante. \\
\hline Objetivo 6 & Participar mais efetivamente dos negócios commodityzados, \\
\hline \hline
\end{tabular}

Quadro 3- Objetivos da destilaria da Copagra.

\subsection{ANÁLISE DO ALINHAMENTO ESTRATÉGICO}

O alinhamento estratégico foi verificado por meio da confrontação dos dados obtidos na diretoria da cooperativa, no setor agrícola e na destilaria. O alinhamento é analisado na lógica de agrupamento, coesão, ajuste, congruência entre diferentes dimensões (Galbraith e Kazanjian 1986) e complexidade e interdependência dos seus sistemas abertos, cujos elementos são formais e informais (Beer e Eisenstat, 1996). A figura 1 auxilia no entendimento do processo analítico utilizado nesse trabalho.

Figura 1- Proposta analítica da pesquisa.

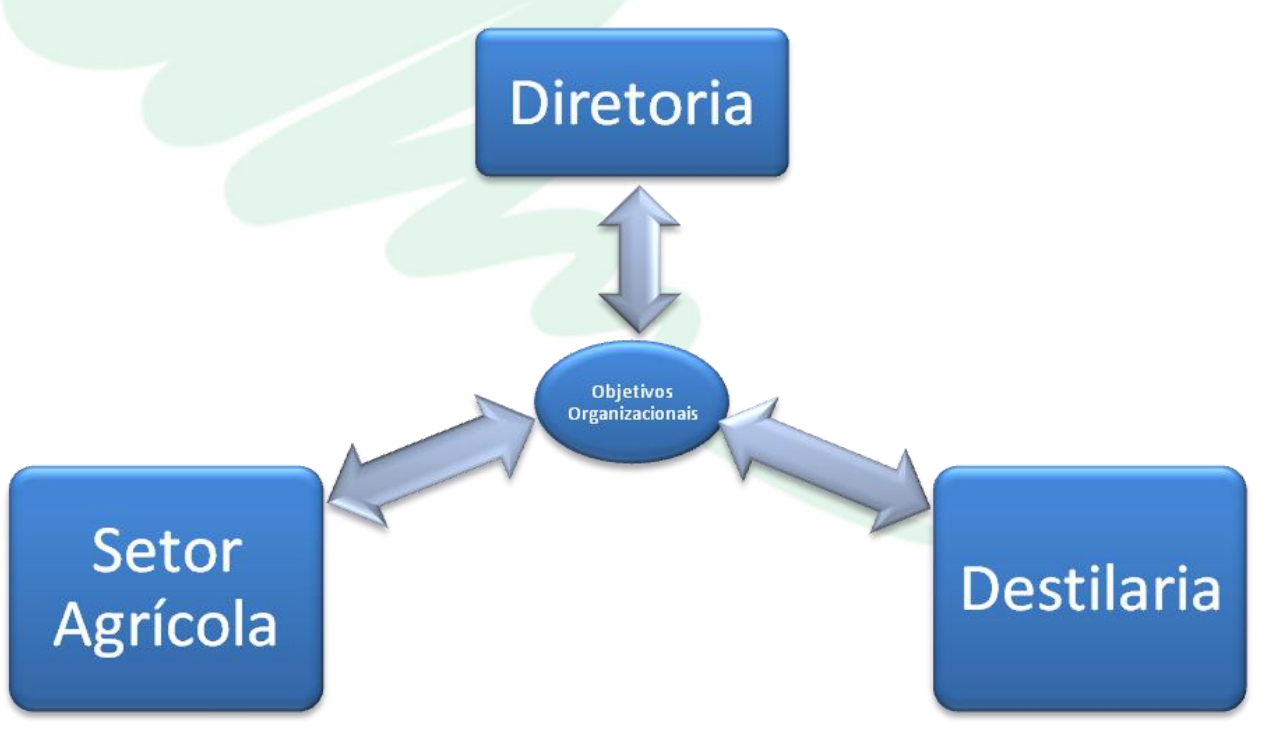

Com relação ao objetivo organizacional de melhorar a qualidade do álcool produzido, foi encontrado um pequeno alinhamento entre os desejos departamentais do setor agrícola e os organizacionais, ou seja, há um alinhamento indireto entre eles, decorrente de suas atividades, porém não foi encontrada explicitação departamental para esse objetivo. O que foi localizado foi o 
Alinhamento Estratégico de Setores Operacionais: O Caso da Cooperativa Agroindustrial do Noroeste do Paraná

desejo do setor em alimentar a destilaria de álcool com a quantidade adequada de matéria-prima, o que representa objetivo primário com quantidade de matéria-prima e, secundário, com a qualidade da matéria-prima, fato que reflete no produto final. Em relação à destilaria, não foi encontrado no rol de intenções dessa unidade a busca desse objetivo organizacional, não existindo, dessa forma, qualquer possibilidade de alinhamento nesse objetivo.

Com relação a atender mercados específicos de etanol, não foi encontrado alinhamento com o setor agrícola, pois em nenhum momento manifesta-se no sentido de sustentar as ações estratégicas de entrada e manutenção em novos mercados específicos. Por outro lado, deparou-se com grande alinhamento com as pretensões da destilaria de álcool em dois de seus objetivos departamentais que são o de auxiliar no aumento da participação de etanol industrial nos negócios da cooperativa e na diversificação do negócio de cana-de-açúcar.

No que tange aumentar a capacidade de produção não foi encontrado alinhamento entre os objetivos organizacionais da destilaria de álcool com os objetivos organizacionais. Em contrapartida, encontrou-se grande alinhamento com os objetivos departamentais do setor agrícola que são: sustentar o crescimento das operações e a minimização da influência climática no processo de CCT.

Não foram encontradas condições de afirmar a existência de algum tipo de alinhamento dos desejos organizacionais com a destilaria de álcool quando se trata da redução estratégica dos custos. Para esse objetivo, foi encontrado grande alinhamento com o setor agrícola, pois quatro de seus objetivos vão nesse sentido, que são: contribuir para a redução dos custos operacionais, autopreparação para a mecanização da colheita, contribuir para a redução dos custos operacionais da cooperativa estudada e a minimização da influência climática no processo de CCT. Esse último objetivo também foi relacionado quando foi realizada a análise do objetivo organizacional de aumentar a capacidade de produção por estar relacionado com os dois objetivos organizacionais.

O objetivo estratégico organizacional de aumentar a eficiência da frota é predominante para o setor agrícola, porém só foi encontrado alinhamento indireto com esse desejo da direção no sentido de manter internamente atividades essenciais para as operações. Com a destilaria de álcool, cliente dos serviços de frota de caminhões não foi encontrado indícios de possível alinhamento com esse objetivo. É valido lembrar que sem um efetivo trabalho na destilaria, de descarga da carga transportada todo o esforço em dar maior eficiência à frota cai por terra.

Por fim, com relação à melhoria da eficiência operacional, foi encontrado alinhamento indireto com os dois setores estudados. Essa afirmação é possível porque a melhoria de eficiência está sendo o cenário para toda a formulação dos objetivos departamentais.

Revista Ibero-Americana de Estratégia - RIAE, São Paulo, v. 10, n. 2, p. 118-139, mai./ago. 2011. 
O quadro 4 sintetiza os encontros a respeito do alinhamento estratégico nos departamentos organizacionais estudados.

\begin{tabular}{|c|c|c|}
\hline OBJETIVO & SETOR AGRÍCOLA & DESTILARIA \\
\hline Melhorar a qualidade do álcool produzido. & Alinhamento indireto & Não encontrado \\
\hline Atender mercados específicos de álcool & Não encontrado & Grande alinhamento \\
\hline Aumentar a capacidade de produção & Grande alinhamento & Não encontrado \\
\hline Redução estratégica dos custos & Grande alinhamento & Não encontrado \\
\hline Aumento da eficiência da frota & Alinhamento indireto & Não encontrado \\
\hline Melhoria da eficiência operacional & Alinhamento indireto & Alinhamento indireto \\
\hline
\end{tabular}

Quadro 4 - Resumo do alinhamento estratégico entre os setores analisados.

A análise dos alinhamentos dos setores estudados permite a afirmação de que o setor agrícola tem preocupações predominantemente operacionais. Parece haver nesse departamento deficiência a respeito do entendimento da organização como um todo. Por outro lado, a destilaria de álcool possui instigação predominantemente mercadológica. Apesar de uma visão mais estratégica, parece que essa unidade de negócios possui pensamentos atomistas em relação a sua participação na cooperativa. Talvez essa unidade não se perceba em uma organização maior.

\section{CONSIDERAÇÕES FINAIS}

Por meio do que foi encontrado, é possível afirmar que, sob o aspecto teórico, a estratégia da organização estudada é formulada por meio de interações sociais (Whittington, 2002), o que, por muitas vezes, não representa a intencionalidade estratégica da alta direção. Tais interações sociais dos integrantes da organização auxiliam as decisões de alocação de recursos (Quinn, 2006; Barney, 1996 e 2006), sem, contudo deixar de ser influenciada pelas forças competitivas da indústria. Esse 
Alinhamento Estratégico de Setores Operacionais: O Caso da Cooperativa Agroindustrial do Noroeste do Paraná

encontro, talvez o mais importante desse artigo, corrobora com parte da literatura contemporânea que admite a diminuição da influência na formalização do processo de estratégico.

De acordo com o que foi encontrado na organização estudada, o alinhamento estratégico parece estar de acordo com o conceitual teórico de Beer e Eisentstat (1996), no sentido de que há interdependência dos sistemas dos elementos formais (tecnologia, estratégia e estrutura) com os informais (pessoas, líderes e valores), para que se dê a implementação eficaz das ações organizacionais (Beer e Eisenstat, 1996). Na organização, também é possível a percepção do alinhamento na lógica de agrupamento, coesão, ajuste, congruência (Galbraith e Kazanjian, 1986). Nesse sentido, o alinhamento, sob a perspectiva do curto e longo prazo (Allio, 2005), não faz sentido para a realidade da organização estudada, pois os setores analisados (diretoria, destilaria e setor agrícola) aparentam não ter em seus objetivos, a proposição de alinhar suas ações de curto prazo para sustentar a estratégia organizacional de longo prazo.

Parece que os setores analisados atuam de forma atomizada, com proposição na defesa interesses particulares e não organizacionais. Esse fato é possível, em razão de que os objetivos organizacionais podem não ter respaldo em toda organização, visto que os objetivos departamentais podem não ir ao encontro dos objetivos da organização. Diante dos dados e da análise, é possível afirmar que parece não existir a efetivação da estratégia (Colla, 2009). Tal efetivação ocorre quando existe a aptidão dos setores organizacionais em realizar ações que sirvam os interesses estratégicos da organização e não os individualizados.

Como sugestão de trabalhos futuros, norteado pela necessidade de criação de um estoque de conhecimento, fica a recomendação de aplicação da metodologia e da parte teórica em todos os setores da organização estudada, bem como também em outras instituições cooperativas. Como forma de minimizar possíveis limitações desse artigo, fica a sugestão de novos estudos que contemplem o alinhamento da organização como um todo e seu ambiente. Também é possível a utilização da base teórica e metodológica em organizações não cooperativas.

Revista Ibero-Americana de Estratégia - RIAE, São Paulo, v. 10, n. 2, p. 118-139, mai./ago. 2011. 


\section{REFERÊNCIAS}

Allio, M. K. (2005). A short, practical guide to implementing strategy. The Journal of Business Strategy, 26(4), 12-21.

http://dx.doi.org/10.1108/02756660510608512

Ansoff, H. I. e McDonnel, E. J. (1993). Implantando a administração estratégica (2 ed). São Paulo: Atlas.

Barney, J. B. (1996). Gaining and sustaining competitive advantage. Massachusetts: AddisonWesley Publishing Company.

Barney, J. B. (2006). Buscando vantagem competitiva internamente. In Mintzberg, H. et al. O processo da estratégica: conceitos, contextos e casos selecionados (4 ed). Porto Alegre: Bookman.

Barros, L. A. M de. (2007). Alinhamento estratégico. Tese de Doutorado, Universidade de São Paulo, São Paulo, SP, Brasil.

Beer, M; Eisenstat, R. A. (1996). Developing an organization capable of implementing strategy and learning. Human Relations, 49(5), 597-619.

http://dx.doi.org/10.1177/001872679604900504

Brodbeck, A. F \& Hoppen, N. (2003). Alinhamento estratégico entre os planos de negócio e de tecnologia de informação: um modelo operacional para implementação. Revista de Administração Contemporânea. 7(3), 9-33.

Bulgacov, S., Souza, Q. R., Prohmann, J. I. de P., Coser, C., \& Baraniuk, J. (2007). Administração estratégica: teoria e prática. São Paulo: Atlas.

Colla, J. E. (2009). A influência da estratégia competitiva e colaborativa no conteúdo estratégico em rede de empresas. Dissertação de mestrado, Universidade Federal do Paraná, Curitiba, PR, Brasil.

Costa, L. S. de V. (2006). O coalinhamento entre as estratégias competitivas e colaborativas como forma de Influenciar o ambiente e melhorar o desempenho de empresas. Tese de Doutorado, Pontifícia Universidade Católica, Rio de Janeiro, RJ, Brasil.

Creswell, J. C. (2007). Projeto de Pesquisa: métodos qualitativo, quantitativo e misto (2 ed.). Porto Alegre: Artmed.

Fahey, L. (1994). Strategic management: today's most important business challenge.In Fahey, L.; Randall, R. M. (Eds.). The portable MBA in strategy. New York: Wiley 
Fernandes Filho, A. (2003). Identificação do grau de alinhamento estratégico da tecnologia de informação com os planos de negócios: o Caso da UNISINOS. Dissertação de Mestrado, Universidade Federal do Rio Grande do Sul, Porto Alegre, RS, Brasil.

Flick, U. (2004). Uma introdução à pesquisa qualitativa (2 ed.) Porto Alegre: Bookman.

Freedman, M. (2003). The genius is in the implementation. The Journal of Business Strategy. 24(2), 26-31. http://dx.doi.org/10.1108/02756660310508164

Galbraith, J. R. \& Kazanjian, R. K. (1986). Strategy implementation: structure, systems and process. St Paul: West Pub.

Gil, A. C. (1991) Como elaborar projetos de pesquisa (3a ed.) São Paulo. Atlas, 1991.

Gimenez, F. A. P. (2000). O estrategista na pequena empresa. Maringá: [ s.n ].

Hair, Jr. J. F., Babin, B., Money, A. H.. \& Samouel P. (2005). Fundamento de Métodos de Pesquisa em Administração. Porto Alegre: Bookman.

Hayashi Junior, P., Baraniuk, J \& Bulgacov, S. A. (2006, setembro). Recursos e competências nas mudanças de conteúdo estratégico em pequenas empresas de massas alimentícias: estudo comparativo de casos. Anais do Encontro Nacional da Associação dos Programas de PósGraduação em Administração, Atibaia, SP, Brasil.

Henderson, J. C. \& Venkatraman, N. (1993). Strategic alignment: leveraging information technology for transforming organizations. IBM System Journal. 32(1), 4-16.

$\underline{\text { http://dx.doi.org/10.1147/sj.382.0472 }}$

Kaplan, R. S. \& Norton, D. (1997). Balanced scorecard: a estratégia em ação (5 ed). Rio de Janeiro: Campus.

Magreta, J. e Stone, N. (2003). O que é gerenciar e administrar. Rio de Janeiro: Elsevier.

May, T. (2004). Pesquisa social: questões, métodos e processos (3 ed.). Porto Alegre: Artmed.

Miles, R. E. \& Snow, C. C. (1984). Fit, Failure and the hall of fame. California Management Review. XXVI(3), n/d.

Mintzberg, H. (2006). Cinco Ps para estratégia. In Mintzberg, H. et al. O processo da estratégica: conceitos, contextos e casos selecionados (4 ed). Porto Alegre: Bookman. 
Mintzberg, H; Ahlstrand, B \& Lampel, J. (2000). Safári de estratégia: um roteiro pela selva do planejamento estratégico. Porto Alegre: Bookman.

Morgan, G., \& Smirich, L. (1980). The case for qualitative research. Academy of Management Review,5(4), $\mathrm{n} / \mathrm{d}$.

Oliveira, A. R. de., Cameira, R. F. \& Caulliraux, H. M. (2003). A visão por processos como elemento alavancador de alinhamento estratégico: o caso de uma empresa prestadora de serviços de transmissão de dados. Anais do X Simpósio de Engenharia de Produção, Bauru, SP, Brasil.

Porter, M. E. (1996). “What is Strategy?”. Harvard Business Review, (nov-dez), 61-78.

(2004). Estratégia competitiva: técnicas para análise de indústria e da concorrência. (16 ${ }^{\mathrm{a}}$ Ed.) Rio de Janeiro: Campus.

(2006). Como as forças competitivas moldam a estratégia. In Mintzberg, $\mathrm{H}$ et al. $O$ processo da estratégica: conceitos, contextos e casos selecionados. p. 95-101. (4 ed.) Porto Alegre: Bookman.

(jan 2008). The five competitive forces that shape strategy. Harvard Business Review. 79-93.

Powell, T. C. (1992). Organizational alignment as competitive advantage. Strategic Management Research News. 29(2), 119-134.

http://dx.doi.org/10.1002/smj.4250130204

Prieto, V. C. (2006). Análise de modelos de alinhamento estratégico interno. Dissertação de Mestrado, Universidade de São Paulo, SP, Brasil.

Prieto, V. C.; Carvalho, M. M. (2004, setembro). Análise do alinhamento estratégico e o impacto nos resultados no setor de medicina diagnóstica. Anais do Encontro Nacional da Associação dos Programas de Pós-Graduação em Administração, Curitiba, PR, Brasil.

Quinn, J. B. (2006). Estratégias para mudança. In Mintzberg, H. et al. O processo da estratégica: conceitos, contextos e casos selecionados (4 ed). Porto Alegre: Bookman.

Richardson, R. J. (1989). Pesquisa social: métodos e técnicas (3a ed.). São Paulo: Atlas.

Synnott, W. R. (1987). The information weapon: winning customers and markets with tecnology.New York: John Wiley and sons.

Triviños, A. N. S. (1987). Introdução à pesquisa em ciências sociais: a pesquisa qualitativa em educação. São Paulo: Atlas. 
Venkatraman, N. \& Camillus, J. C. (1984). Exploring the concept of „fit " in strategic management. Academy of Management Review. 9(3), 513-525. http://dx.doi.org/10.5465/AMR.1984.4279696 http://dx.doi.org/10.2307/258291

Venkatraman, N. (jan 1990). Performance implications of strategic coalignment: a methodological perspective. Journal of Management Studies, 19-41.

http://dx.doi.org/10.1111/j.1467-6486.1990.tb00751.x

Whittington, R. (2002). O que é estratégia. São Paulo: Pioneira Thomson Learning.

Wright, P; Kroll, M. J. \& Parnell, J. (2000). Administração estratégica: conceitos. São Paulo: Atlas.

Wunder(2005), T. New estrategic alignment in multinational corporations. Strategic Finance. Montvale. 87(5), 35-41.

Recebido: 25/05/2011

Aprovado: 03/08/2011

Revista Ibero-Americana de Estratégia - RIAE, São Paulo, v. 10, n. 2, p. 118-139, mai./ago. 2011. 